\title{
EFFECTS OF THE PLATELET-RICH FIBRIN (PRF) ON BONE DENSITY IN IMMEDIATE IMPLANT PLACEMENT AND LOADING IN ESTHETIC ZONE (A RANDOMIZED CLINICAL TRIAL)
}

\author{
Shaaban Metwally Ahmed Adel*, Fahmy Ahmed Mohamed**and El Khourazaty Nada Sherin ${ }^{* * *}$
}

\begin{abstract}
Aim of the study: The aim of this study was to evaluate the effect of PRF on bone density after immediate implant placement and loading in the esthetic zone.

Material and Methods: Patients were selected from the outpatient Dental Implant Clinic Faculty of Dentistry, Cairo University, based on certain inclusion and exclusion criteria. The patients were divided into two equal groups: Group A: Immediate implant placement and loading with PRF in the jumping gap at site of unrestorable extracted teeth in esthetic zone. Group B: (Conventional) immediate implant placement and loading without PRF in jumping gap at site of unrestorable extracted teeth in esthetic zone. After implant placement and loading, CBCTs were taken at 0,3,6,9 month. Bone density was measured at 0,3,6,9 month for both groups. The collected results were tabulated and statistically analyzed and the significance level was set at $\mathrm{P} \leq 0.05$.
\end{abstract}

Results: The results of this study showed that the PRF group had higher bone density and there was statistically significant difference between (PRF) and (no PRF) groups in bone density values in 3,6 and 9 months intervals.

Conclusion: The use of PRF as a jumping gap grafting material in immediate implant placement and loading enhance bone density around implant placed in the esthetic zone. Immediate implant placement and loading by using PRF in the jumping gap as a grafting material is a predictable and effective procedure for enhancing bone density around implants.

KEYWORDS: Platelet-Rich Fibrin (PRF), Bone Density In, Immediate Implant Placement, Immediate Implant Loading.

\footnotetext{
* Master Degree in Implantology Faculty of Dentistry Cairo University

** Ass. Professor of Removable Prosthodontics, Faculty of Dentistry, Cairo University

*** Associate Professor of Prosthodontics, Faculty of Dentistry Cairo University
} 


\section{INTRODUCTION}

Unrestorable teeth and edentulous spaces either in the maxilla, mandible or both present many problems varying from functional, esthetic and comfort related problems. ${ }^{1}$ Patients with these problems usually seek a prosthesis as soon as possible. A while ago the conventional removable acrylic resin dentures were the only way to restore the extracted teeth and edentulous ridges but it was rejected by many patients for many reasons as lack of retention and stability, bad esthetics and many of them prefer the fixed restorations. After the dental implants invaded the dental world and become a magical option for many hopeless patients to have good esthetic functional restorations. The restorations for those patients became easier and not compared to the old conventional prosthesis. There are several treatment options to place dental implants which differs in implants number and positions and the type of prosthesis, but the most concerning factors for patients is time rather than decreasing the number of surgical procedures needed and preserving the remaining alveolar bone and subsequently maintaining the normal soft tissue profile which could be of major importance in the esthetic zone ${ }^{2,3}$. This lead to presence of immediate, early, delayed implant placement and immediate loading concept and then early loading rather than conventional loading protocol. Each protocol have its benefits and its limitations and requirements. ${ }^{4,5}$. Platelet rich fibrin (PRF) is now commonly used in conjunction with implants to enhance healing and bone quality. (Acres et al, 1985) ${ }^{6}$ and (Chang et al, 2010) ${ }^{7}$ discussed the effect of platelet growth factors on proliferation of osteoblasts to enhance the bone density and other cells. They found on their studies the PRF induced a significant and continuous stimulation of proliferation in all cell type, The PRF is a low priced and easy to obtain autogenous material. It has slowly releases significantly amounts of growth factors (TGF B1, PDGF-AB, VEGF) and thrombospondin-1 (TSP-1) during at least seven day, it was considered as a healing biomaterial with potential beneficial effect on peri-implant tissue.
(Moraschini,V \& Barboza, 2015) ${ }^{8}$ and (Slagter, K. W. et al. - 2014) ${ }^{9}$ Presents some papers on immediate placement of dental implants their shifted from implant survival toward optimal preservation of soft and hard tissues. They found on their studies implant survival, minimum peri-implant hard and soft tissue changes, good esthetic outcome, and patient satisfaction of immediately placed single tooth implants in the esthetic zone. Also the atrumatic operating technique and immediate insertion of the implant resulted in the preservation of the hard and soft tissues at the extraction site. Also the Immediate placement with immediate temporization of dental implants in the esthetic zone results in an excellent short-term treatment outcome in terms of implant survival and minimal change of peri- implant soft and hard tissue dimensions.

The aim of this study was to evaluate the effect of PRF on bone density after immediate implant placement and loading in the esthetic zone. The hypothesis of this study was that the placement of PRF during immediate implant insertion and loading would have an effect on bone density.

\section{MATERIAL AND METHODS}

The included patients (male and female) had unrestorable tooth in esthetic zone which extend from right second premolar to the left one, with no systematic or local contraindication for implant placement. Age ranged from 20 to 45 years. Only non-diabetic patients were included, which was confirmed by glycosylated HB test ${ }^{10}$. Patients with adequate bone height apical to the alveolus of the failing tooth with at least $3 \mathrm{~mm}$ bone were required to ensure primary implant stability ${ }^{11},{ }^{12}$. Non-smoker patients or Patients smoking less than 10 cigarettes per day were included in the study ${ }^{13}$. Sufficient bone width $(\geq 1 \mathrm{~mm})$ in the buccal plate of the remaining root to place an implant ${ }^{14}$. This was confirmed by cone beam computed tomographic (CBCT) ${ }^{15}$.Only compliant and cooperative patients with good oral hygiene were included. 
Exclusion criteria: Patients suffering from systematic disease which may affects osteointgration (uncontrolled diabetes, cancer, etc...), patients with bad oral hygiene and uncooperative patients. Also, patients with abnormal habits such as bruxism, clenching, deep bite, edge to edge and parafunctional habits ${ }^{16}$ as well as Pregnant patients and heavy smokers were excluded ${ }^{13}$. Patients with severe infection such as acute pulpitis, periapical periodontitis, and acute abscess were excluded ${ }^{17}$. Patients with loss of the labial crest after extraction of the failing tooth were excluded ${ }^{18}$.

Patient examination: The included patients were asked for previous dental history and extra oral examination were carried out.

Radiographic examination: CBCT made for the patients to evaluate the amount of bone present buccally and apically preoperatively ${ }^{19}$.

Preparation phase: The vacuum stent was prepared on the duplicated cast obtained from study cast after waxing-up of the missed tooth.

Surgical phase: $\mathrm{PRF}$ preparation: Ablood sample from each patient was taken without anticoagulant in $10-\mathrm{mL}$ tubes which were immediately centrifuged at $3000 \mathrm{rpm}$ for 10 minutes (80-2 Electronic Laboratory Medical Centrifuge - China). Fibrinogen is initially concentrated in the high part of the tube, before the circulating thrombin transforms it into fibrin. A fibrin clot is then obtained in the middle of the tube, just between the red corpuscles at the bottom and a cellular plasma at the top by using a tissue forceps and then speared it from blood clot by small scissor ${ }^{20-22}$.After PRF preparation atraumatic extraction was initiated with periotome (SedraPakistan) to cut the periodontal ligament ${ }^{23}$. After complete loosening of remaining root, the root was extracted by forceps then gentle curettage of the socket and irrigation by saline was performed, checking of the buccal plate of bone by periodontal probe was done for detection of any fenestrations. Drilling was started by lindemann drill (DENTIS ONE Q Surgical Kit - korea) apically in an up and down motion on the palatal wall of the single rooted tooth and on the buccal wall of the palatal root or throughout interseptal bone of premolars, followed by a pilot and sequential drilling until reaching the final drill. A parrelling pin was used between the drills to ensure the correct position and angulation guided by the surgical stent. After drilling the osteotomy site was irrigated by saline. The implant (DENTES ONE Q ,sand blasted large grit acid etching surface treatment SLA - Korea) was threaded by hand and followed by a hex tool and a ratchet until the implant platform reached to $2 \mathrm{~mm}$ below cementoenamel junction of neighboring tooth and confirm it sub bony by minimum $1 \mathrm{~mm}$ to the buccal bone $e^{2,9,24}$. After the implant was placed and confirm the jumping gap between implant and labial bone was between $2-3 \mathrm{~mm}$, the PRF was applied in the jumping gap and properly adapted by condenser and tissue forceps. Fig (1) Suturing around the inserted implant and abutment was done in an interrupted suture pattern by resorbable 50 vicryl suture (Pegesorb dogsan 20mm 3/8 cuttingEgypt). Fig (2). Temporization was made by using vacuum stent and dual cure resin material (3M ESPE Protemp-United States). After securing temporary abutment and its preparation to ensure it is out of occlusion and checking the seating of the stent, injection of the protemp material was done and reseating of the stent till setting the material, removal of the stent, then finishing and polishing was done and the screw-retained crown was secured to implant and occlusion was checked to using articulating paper (40 micron thickness) that passed without any interfaces. Fig. (3)

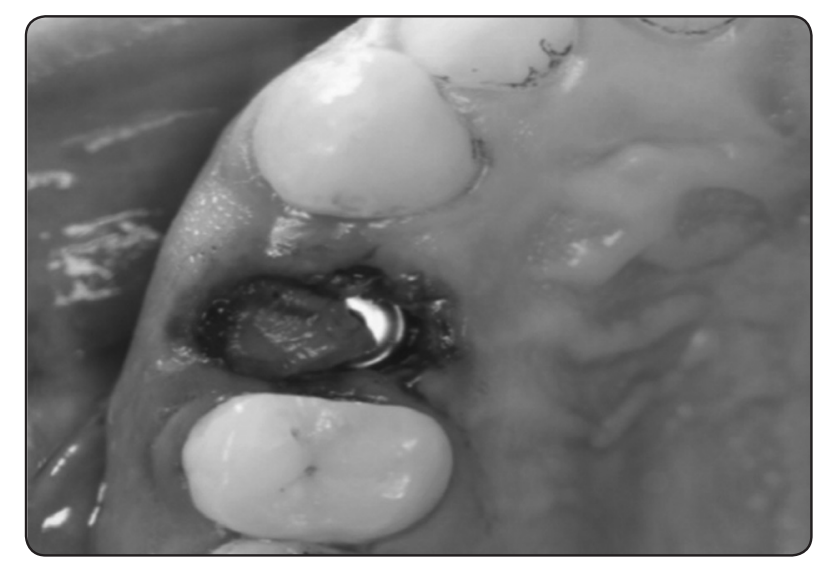

Fig. (1): PRF in jumping gap. 


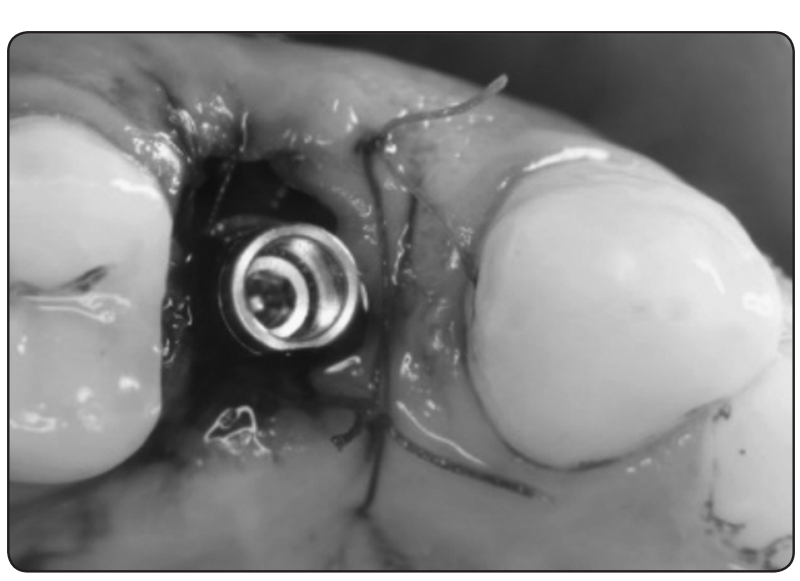

Fig. (2) Suturing around the implant

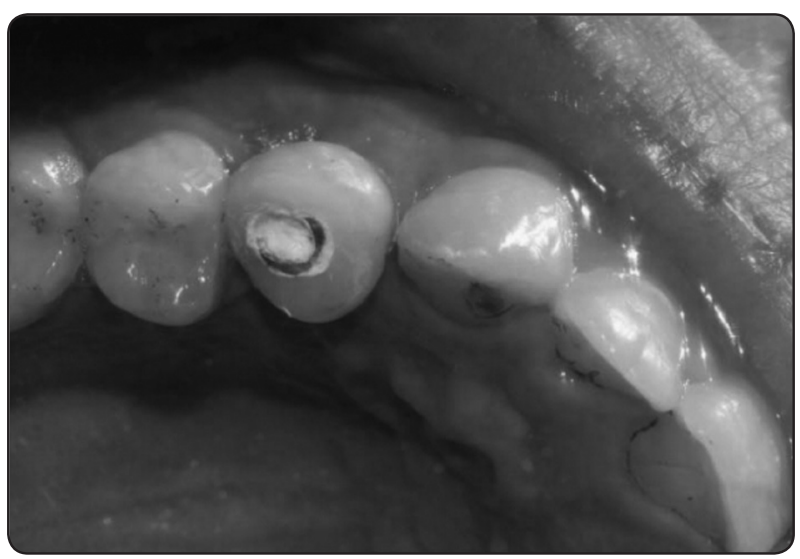

Fig. (3) Screw retained temporary crown

Prosthetic phase: After 3 months from implant placement, the temporary crown was removed and impression was tacked by closed tray impression technique. An impression transfer was screwed to the implant and impression was taken by condensation silicon putty and light (Zeta plus-Italy) in one step. The impression was sent to the lab to fabricate a porcelain fused to metal crown on the abutment and was delivered in the usual manner.

Patient recall: The patients were recalled every 3 month and CBCTs (Planmeca-Finland) were done at $0,3,6,9$ months after implant insertion.

\section{RESULTS}

The mean and standard deviation values were calculated for each group in each test. Data were explored for normality using Kolmogorov-Smirnov and Shapiro-Wilk tests, data showed parametric (normal) distribution. Independent sample t-test was used to compare between two groups in nonrelated samples. Repeated measure ANOVA was used to compare between more than two groups in related samples. Paired sample t-test was used to compare between two groups in related samples. Two-way ANOVA was used to test the interaction between variables. The significance level was set at $\mathrm{P} \leq 0.05$. Statistical analysis was performed with IBM ${ }^{\circledR}$ SPSS ${ }^{\circledR}$ Statistics Version 20 for Windows.

\section{Bone Density results:}

\section{A) Effect of time:}

Group I (With PRF): There was a statistically significant difference between $(0 \mathrm{~m}),(3 \mathrm{~m}),(6 \mathrm{w})$ and $(9 \mathrm{~m})$ groups where $(\mathrm{p}=0.003)$. A statistically significant difference was found between $(0 \mathrm{~m})$ and each of $(3 \mathrm{~m}),(6 \mathrm{~m})$ and $(9 \mathrm{~m})$ groups where $(\mathrm{p}=0.001),(\mathrm{p}<0.001)$ and $(\mathrm{p}<0.001)$, respectively. No statistically significant difference was found between $(3 \mathrm{~m})$ and each of $(6 \mathrm{~m})$ and $(9 \mathrm{~m})$ where $(\mathrm{p}=0.001)$ and $(\mathrm{p}<0.001)$, respectively. Also, a statistically significant difference was found between $(6 \mathrm{~m})$ and $(9 \mathrm{~m})$ groups where $(p=0.022)$. (Table 1, Figure 4)

Group II (Without PRF): There was a statistically significant difference between $(0 \mathrm{~m})$, $(3 \mathrm{~m}),(6 \mathrm{w})$ and $(9 \mathrm{~m})$ groups where $(\mathrm{p}=0.001)$. A statistically significant difference was found between $(0 \mathrm{~m})$ and each of $(3 \mathrm{~m}),(6 \mathrm{~m})$ and $(9 \mathrm{~m})$ groups where $(\mathrm{p}=0.006),(\mathrm{p}=0.001)$ and $(\mathrm{p}<0.001)$, respectively. No statistically significant difference was found between $(3 \mathrm{~m})$ and each of $(6 \mathrm{~m})$ and $(9 \mathrm{~m})$ where $(\mathrm{p}=0.009)$ and $(\mathrm{p}<0.001)$ respectively. Also, a statistically significant difference was found between $(6 \mathrm{~m})$ and $(9 \mathrm{~m})$ groups where $(\mathrm{p}=0.002)$. (Table 1, Figure 4) 
TABLE (1) The mean, standard deviation (SD) values and statistical analysis of bone density as affected by time for different groups.

\begin{tabular}{|c|c|c|c|c|c|}
\hline \multirow{3}{*}{ Variables } & \multicolumn{5}{|c|}{ Density } \\
\hline & \multicolumn{2}{|c|}{$\begin{array}{c}\text { Group I } \\
\text { With PRF }\end{array}$} & \multicolumn{2}{|c|}{$\begin{array}{c}\text { Group II } \\
\text { Without PRF }\end{array}$} & \multirow{2}{*}{$\mathrm{p}$-value } \\
\hline & Mean & SD & Mean & SD & \\
\hline $0 \mathrm{~m}$ & 572.77 & 33.29 & 568.38 & 47.18 & $0.856 \mathrm{~ns}$ \\
\hline $3 \mathrm{~m}$ & 712.12 & 32.70 & 663.97 & 34.12 & $0.032 *$ \\
\hline $6 \mathrm{~m}$ & 979.57 & 82.86 & 800.05 & 53.88 & $0.001 *$ \\
\hline $9 \mathrm{~m}$ & 1139.20 & 65.51 & 972.45 & 64.18 & $0.001 *$ \\
\hline p-value & \multicolumn{2}{|c|}{$0.003^{*}$} & \multicolumn{2}{|c|}{$0.001 *$} & \\
\hline
\end{tabular}

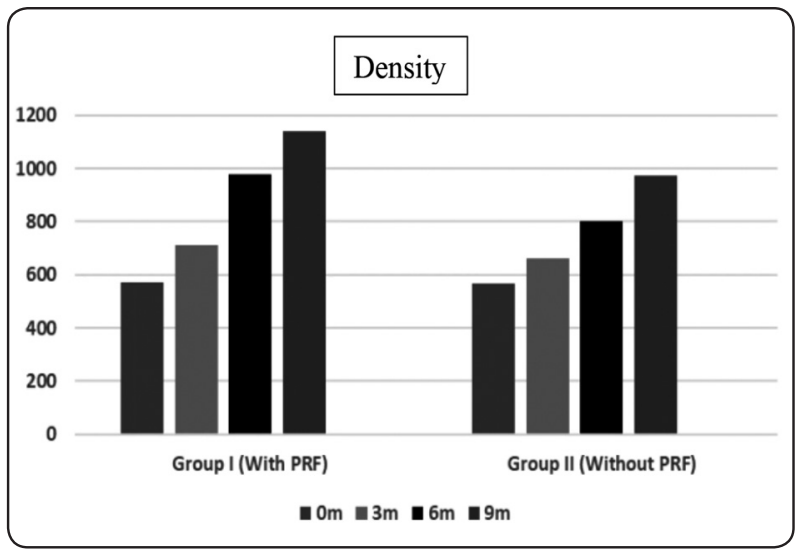

Fig. (4) Bar chart representing bone density as affected by time for different groups

\section{B) Effect of PRF on bone density:}

0m : There was no statistically significant difference between (PRF) and (Conventional) groups where $(p=0.856)$. 3m: There was a statistically significant difference between (PRF) and (Conventional) groups where $(p=0.032)$. 6m: There was a statistically significant difference between (PRF) and (Conventional) groups where $(p=0.001)$. 9m: There was a statistically significant difference between (PRF) and (Con- ventional) groups where $(p=0.001)$. (Table 2, Figure 5)

TABLE (2) Effect of PRF on bone density in both groups.

\begin{tabular}{|c|c|c|c|c|c|}
\hline \multirow{2}{*}{} & \multicolumn{5}{|c|}{ Density } \\
\cline { 2 - 6 } & $\begin{array}{c}\text { Group I } \\
(\text { With PRF) }\end{array}$ & SD & $\begin{array}{c}\text { Group II } \\
\text { (Without PRF) }\end{array}$ & SD & p-value \\
\hline $0 \mathrm{~m}$ & 572.77 & 33.29 & 568.38 & 47.18 & $0.413 \mathrm{~ns}$ \\
\hline $3 \mathrm{~m}$ & 712.12 & 32.7 & 663.97 & 34.12 & $0.136 \mathrm{~ns}$ \\
\hline $6 \mathrm{~m}$ & 979.57 & 82.86 & 800.05 & 53.88 & $0.732 \mathrm{~ns}$ \\
\hline $9 \mathrm{~m}$ & 1139.2 & 65.51 & 972.45 & 64.18 & $0.039 *$ \\
\hline
\end{tabular}

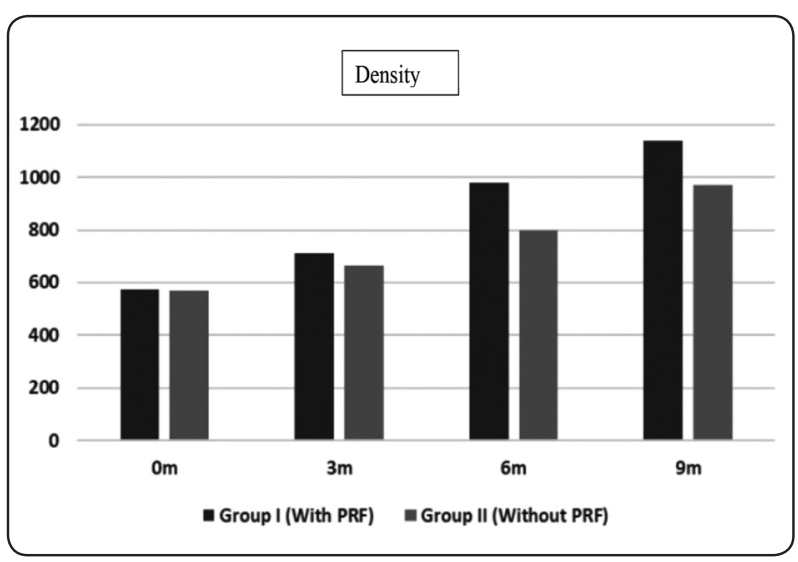

Fig. (5) Bar chart representing bone density for different groups as affected by PRF

\section{C) Effect of different interactions}

The results of Two-way ANOVA analysis for the interaction of different variables. The results showed that different groups (with and without PRF) had a statistically significant effect at P-value $<0.001$. Also, time had a statistically significant effect at $\mathrm{P}$-value $<0.001$. Additionally, he interaction between the two variables had a statistically significant effect at P-value $<0.001$ on bone density. (Table 3) 
TABLE (3) Results of Two-way ANOVA for the effect of different variables on density.

\begin{tabular}{|l|l|l|l|l|l|}
\hline Source & Type III Sum of Squares & Df & Mean Square & F & Sig. \\
\hline Corrected Model & 1851243.706 & 7 & 264463.387 & 89.098 & .000 \\
\hline Intercept & 30801654.188 & 1 & 30801654.188 & 10377.132 & .000 \\
\hline Groups(with \& withoutPRF) & 119281.080 & 1 & 119281.080 & 40.186 & .000 \\
\hline Time & 1664135.409 & 3 & 554711.803 & 186.883 & .000 \\
\hline Groups* Time & 67827.217 & 3 & 22609.072 & 7.617 & .000 \\
\hline Error & 118728.967 & 40 & 2968.224 & & \\
\hline Total & 32771626.860 & 48 & & & \\
\hline Corrected Total & 1969972.673 & 47 & & & \\
\hline
\end{tabular}

$d f:$ degrees of freedom $=(n-1), *$ Significant at $P \leq 0.05$

\section{DISCUSSION}

This study was planned on the assumption that the placement of PRF during immediate implant insertion and loading will have an effect on bone density ${ }^{10,25-27}$. All the patients' teeth were extracted atraumaticlly by using periotome since its known for being less invasive with a decrease operative time, rapid healing, fewer complication and increased patient comfort. Immediate implant placement is preferred than early and late placement, due to its reduced overall treatment time and preservation of bone width and height ${ }^{28}$. Ideal location mesiodistally and harmony with the adjacent teeth, natural scalloping and papillae are easier to achieve, and maximum soft tissue support ${ }^{29}$. Also, optimal space availability to place the implant, only one surgical procedure. Immediate placement depends on the amount of bone remaining after extraction especially in the apical area beyond the root and the amount of infection or lesion present it's the absence of any lesion or mild infection is preferred ${ }^{30}$. All selected cases had intact buccal and palatal plate of bone, absence of infection, thick tissue biotype and presence of at least $2 \mathrm{~mm}$ bone apical to decayed tooth to ensure primary stability. Initial stability in immediate placement is important to gain implant success. The implants were immediately loaded since immediate loading with provisional restoration with the temporary abutment gained high success rate. The problem of immediate loading is the effect on the stability of the dental implant, so growth factor such as PRF was introduced in the osteotomy site to enhance the primary stability of dental implants ${ }^{31,32}$.

The use of cylindrical and surface modified implants showed a stronger bone response than machined implants in immediate implant placement particularly and increase the contact between implants and new bone formation which helps to improve the stability of implant and enhance bone density ${ }^{33}$.

In the present study bone density was evaluated around implant with PRF and without PRF at day of surgery and after 3, 6, 9 months s $^{25,27,34}$.

The results of this study showed that there was no difference regarding bone density around 
immediately placed implants with the addition of PRF and without PRF as the CBCT was taken at the day of surgery right after implant placement. The results of this study showed that there was a statistically significant difference in bone density around immediately placed implants with the addition of PRF and without PRF at 3,6,9 month that may be due to the effect of time in which they explained PRF has an early but short-term beneficial effect on the process of Osseo integration as reflected by increased implant stability, and PRF membrane is an autogenous material with properties that benefit tissue regeneration, which renders its manipulation around prosthetic abutments easier during fitting. It may be used as a protective barrier for alloplastic material placed in the oral cavity, and as an alternative to periosteal incision when the dental surgeon opts for synthesis. Extraction sockets mostly heals uneventfully. After extraction there is bone growth in the socket but there is resorption of the alveolar ridges also which is welldocumented. The greatest amount of bone loss is in the horizontal dimension and occurs mainly on the facial aspect of the ridge. Loss of vertical ridge height has been described to be most pronounced on the buccal aspect ${ }^{35}$. The results of this study showed that there was a statistically significant difference in the bone density throughout the period of $0,3,6,9$ time in the same group maybe due to the effect of time. The increase in bone density observed with the PRF group in this study can be attributed to the presence of the PRF membrane which slowly release significant amount of fibrin with growth factor (TGF $\beta 1$, PDGF-AB, VEGF and thrombin) during the first seven days which accelerate the healing process and stimulate tissue generation. These components can be effective in regulating the proliferation, differentiation and apoptosis of repair related cells, and subsequently regulating and promoting tissue repair. PRF has been reported to enhance angiogenesis, support immunity, and to enhance the coverage of injured tissues through its positive effect on epithelial cells and fibroblasts ${ }^{36}$. On the other hand the commonly used alloplastic membrane that are easily handle and place by the surgeon nowadays not only increase infection risks when compare to the autogenous material but also the added costs involved in the membrane production.

The effect of PRF on soft tissues in controversial. (Joseph Choukroun, 2006) ${ }^{37}$ reported a strong effect of plasma rich in growth factors on the human gingival fibroblasts in vitro. Dohan Ehrenfest et al. (2009) 37 also reported a strong stimulation of proliferation of PRF on human gingival fibroblasts. In contrast, the clinical evaluation reported in our study, revealed no evidence to support a beneficial role of PRF on peri-implant soft tissues including the gingival health and peri-implant pocket depth, which is in agreement with Boora et al. $(2015)^{38}$. The immediate implant temporization by itself aids in the maintenance of the gingival health, and hence could have masked the effect of the PRF on the gingival tissues. The limited sample size, is another factor that could also have contributed to this result. In contrast to the results of this study, Boora $(2015)^{38}$ reported lower marginal bone loss associated with PRF in single staged, immediately temporized dental implants placed in maxillary anterior region. The insignificant difference reported in our study is probably related to the short term effect of the PRF. By time, the effect of PRF fades away and the inheretent properties of alveolar bone prevails. Consequently, most successful implants have a comparable trivial and insignificant crestal bone loss on the long term evaluation.

\section{RECOMMENDATION}

Within limitation of this study such as drop out patients and failures, so the recommendation for more follow up period and more study for measuring effect of PRF on soft and hard tissue. 


\section{REFERENCES}

1. Al-Omiri, M., Hantash, R. A. \& Al-Wahadni, A. Satisfaction with dental implants: A literature review. Implant Dent. 14, 399-408 (2005).

2. Park, J.-B. Immediate Placement of Dental Implants Into Fresh Extraction Socket in the Maxillary Anterior Region: A Case Report. J. Oral Implantol. 36, 153-157 (2010).

3. Pagni, G., Pellegrini, G., Giannobile, W. V. \& Rasperini, G. Postextraction Alveolar Ridge Preservation: Biological Basis and Treatments. International Journal of Dentistry 2012, 1-13 (2012).

4. Misch CE1, Wang HL, Misch CM, Sharawy M, Lemons J, J. K. Rationale for the application of immediate load in implant dentistry: Part I. Implant Dent. 2004 Sep;13(3)20717. 13, 207-17 (2004).

5. The SAC classification in implant dentistry. Quintessence Publication Co Ltd, 2009. Timing_of_Implant_Placement_in_Anterior_Zone_A_Cli.(2009)

6. Acres, R. B., Lamb, J. R. \& Feldman, M. Effects of platelet-derived growth factor and epidermal growth factor on antigen-induced proliferation of human T-cell lines. Immunology 54,9-16 (1985).

7. Chang, I., Tsai, C. \& Chang, Y. Platelet-rich fibrin modulates the expression of extracellular signal- regulated protein kinase and osteoprotegerin in human osteoblasts. J. Biomed. Mater. Res. 95A, 327-332 (2010).

8. Moraschini, V. \& Barboza, E. S. P. Effect of autologous platelet concentrates for alveolar socket preservation : a systematic review. Int. J. Oral Maxillofac. Surg. (2015).

9. Slagter, K. W. et al. Immediate Placement of Dental Implants in the Esthetic Zone: A Systematic Review and Pooled Analysis. J. Periodontol. 85, e241-e250 (2014).

10. Aguilar-Salvatierra, A. et al. Peri-implant evaluation of immediately loaded implants placed in esthetic zone in patients with diabetes mellitus type 2: A two-year study. Clin. Oral Implants Res. 27, 156-161 (2016).

11. Single-tooth replacement in the anterior maxilla by means of immediate implantation and provisionalization: A review. J. Prosthet. Dent. 101, 230 (2009).

12. Den Hartog, L., Huddleston Slater, J. J. R., Vissink, A., Meijer, H. J. A. \& Raghoebar, G. M. Treatment outcome of immediate, early and conventional single-tooth implants in the aesthetic zone: A systematic review to survival, bone level, soft-tissue, aesthetics and patient satisfaction. J. Clin. Periodontol. 35, 1073-1086 (2008).
13. Takamiya, A., Goiato, M. \& Filho, H. Effect of smoking on the survival of dental implants. Biomed. Pap. Med. Fac. Univ. Palacky. Olomouc. Czech. Repub. 158, (2013).

14. Levine, R. et al. 10 Keys for Successful Esthetic-Zone Single Immediate Implants. Compendium 38, 248-260 (2017).

15. Nagarajan, A., Perumalsamy, R., Thyagarajan, R. \& Namasivayam, A. Diagnostic imaging for dental implant therapy. J. Clin. Imaging Sci. 4, 4 (2014).

16. Renato, P., Zuim, J. \& Brandini, D. A. Relation between bruxism and dental implants. 371-376 (2014).

17. Villa, R. \& Rangert, B. Immediate and early function of implants placed in extraction sockets of maxillary infected teeth: A pilot study. J. Prosthet. Dent. 97, S96-S108 (2007).

18. Chu, S. Subclassification and Clinical Management of Extraction Sockets with Labial Dentoalveolar Dehiscence Defects. Compend. Contin. Educ. Dent. 36, 516-525 (2015).

19. Jyoti, B., Gupta, M., mishra, pankaj \& Srivastava, R. Cone beam computed tomography: A new vision in dentistry. Digit. Med. 1, 7-16 (2015).

20. Choukroun, J., Diss, A., Simonpieri, A. \& Girard, M. Platelet-rich fibrin ( PRF ): A second-generation platelet concentrate . Part V: Histologic evaluations of PRF effects on bone allograft maturation in sinus lift. Oral Surg Oral Med Oral Pathol Oral Radiol Endod. 101, 299-303 (2006).

21. Sharma, M., Lone, P. A., Singh, R. \& Waheed, A. Effects of autologous platelet rich fibrin in bone regeneration in post-extraction mandibular sockets. 4, 309-313 (2018).

22. Choukroun, J., Diss, A., Simonpieri, A. \& Girard, M. Platelet-rich fibrin ( PRF ): A second-generation platelet concentrate . Part V : Histologic evaluations of PRF effects on bone allograft maturation in sinus lift. Oral Surg Oral Med Oral Pathol Oral Radiol Endod. 101, 299-303 (2006).

23. Andersen, E., Haanaes, H. R. \& Knutsen, B. M. Immediate loading of single-tooth ITI implants in the anterior maxilla: a prospective 5-year pilot study. Clin. Oral Implants Res. 13, 281-287 (2002).

24. Arora, S. RESEARCH ARTICLE A Comparative Evaluation of Immediate Implant Placement in Fresh Extraction Socket with and without the Use of Platelet-rich Fibrin : A Clinical and Radiographic Study.4, 48-58 (2015) 
25. Yang, C. Feasibility of CBCT in Evaluating Bone Density of Dental Implant Placement Sites. Research \& Reviews: Journal of Dental Sciences 5, 87-91 (2017).

26. Cabello, G., Rioboo, M. \& Fábrega, J. G. Immediate placement and restoration of implants in the aesthetic zone with a trimodal approach: Soft tissue alterations and its relation to gingival biotype. Clinical Oral Implants Research 24, 1094-1100 (2013).

27. Cassetta, M., Stefanelli, L. V., Pacifici, A., Pacifici, L. \& Barbato, E. How accurate is CBCT in measuring bone density? A comparative CBCT-CT in vitro study. Clinical Implant Dentistry and Related Research 16, 471-478 (2014).

28. Van Nimwegen, W. G. et al. Immediate implant placement and provisionalisation in the aesthetic zone. J. Oral Rehabil. 43, 745-752 (2016).

29. Chen, S. T., Darby, I. B., Reynolds, E. C. \& Clement, J. G. Immediate Implant Placement Postextraction Without Flap Elevation. J. Periodontol. 80, 163-172 (2009).

30. Villa, R. \& Rangert, B. Immediate and early function of implants placed in extraction sockets of maxillary infected teeth: A pilot study. J. Prosthet. Dent. 97, (2007).

31. Blus and Szmukler-Moncler, 2010, C. Blus, S. S.M., Loading, A. tooth extraction and immediate implant placement with piezosurgery: evaluation of 40 sites after at least 1 year of \& Int. J. Periodontics Restorative Dent., 30 (2010), pp. 355-363.
32. Shaker, A. E.-S. The Role of Platelets Rich Fibrin in Immediately Loaded Dental Implants: A Prospective Randomized Controlled Clinical Trial. J. Am. Sci. 12, 55-62 (2016).

33. Alves, C. C. \& Neves, M. Tapered implants: from indications to advantages. The International journal of periodontics \& restorative dentistry 29, 161-7 (2009).

34. Ghoncheh, Z. et al. Assessment of the Capability of Bone Density Contrast Dissociation in Cone Beam Computed Tomography Compared to Digital Periapical Radiography by Using a Phantom. J. Dent. (Shiraz, Iran) 20, 203-209 (2019).

35. Srinivas, B. et al. Wound Healing and Bone Regeneration in Postextraction Sockets with and without Platelet-rich Fibrin. Ann. Maxillofac. Surg. 8, 28-34 (2018).

36. Clementini, M. et al. Dimensional changes after immediate implant placement with or without simultaneous regenerative procedures: a systematic review and meta-analysis. Journal of clinical periodontology 42, 666-677 (2015).

37. Dohan Ehrenfest, D. M. et al. In vitro effects of Choukroun's PRF (platelet-rich fibrin) on human gingival fibroblasts, dermal prekeratinocytes, preadipocytes, and maxillofacial osteoblasts in primary cultures. Oral Surgery, Oral Med. Oral Pathol. Oral Radiol. Endodontology 108, 341-352 (2009).

38. Boora et al .Clinical evaluation of implant survival based on size and site of placement. Clin. Oral Implants Res. 26, 448 (2015). 